\title{
The Truth Imperative
}

\section{ALPHONSO LINGIS}

The Pennsylvania State University

Certainly it would be foolish to posit, in a species as wily and mendacious as our own, something like a primitive, irreducible will to truth--and Kant does not do so. And if the will to truth which regulates the procedures of pure speculative reason is to be founded in practical reason, this certainly does not mean that the will to truth is sustained by some presumed evidence of its utility for human nature, that is, for sensuous human nature lured by pleasures, afflicted with the phantasm, the phantom goal, of happiness. The unconditional will to truth, the will to not allow oneself to be deceived, is a special case of the will to not decelve; it cannot. Nietzsche has argued, owe its origin to a calculus of utility; the cunning of our reason, It's concelts and decelts, prove their utility every day. What imperative then makes the soul truthful? And how?

\section{The Command to be in Command}

The mind has the power, but not the inclination, to think. It thinks on command. The force of law is, for Kant, a fact. It is the first fact: facts can be conceived as facts in the measure that they can be apprehended by a thought ordered by law--ordered not first by the universal and necessary laws of thought, but by the exigency for the universal and the necessary, the imperative for laws. What is primary is not a subjection of the mind to the layout of real things, what Heldegger calls ontological truth or truthfulness, but rather, in Kant as in Heidegger too, consclence. Conscience in Heidegger is subjection to the imperative of death; it is, for Kant, subjection to law, that is, to the exigency for the universal and the necessary. Concepts of what 18 always and everywhere found in things, propositions formulating principles, are formed by a mind that is subject to law, and because it is subjected. Thought is obedience.

The sense of law is not formed in a concept; law is not something that exists for the mind because the mind comprehends it, that 18, produces it in a synthetic a priori judgment. The mind that conceives, that synthe- 
sizes data in representations, is already subject to law. One cannot ask if law is valid and true, and how that could be known. Before law is conceived, formulated, understood, it is obeyed. It is because the mind's substance is receptive to the exigency for law that it can activate itself to think coherently and consistently. This receptivity, this passivity or this passion, this passive subjection which precedes and makes possible the first consistent formulation of an act of thought, is an intellectual feeling, the feeling in which the intellect is born; Kant calls it the sentiment of respect. Respect is, Kant says, something like fear, something like inclination. The mind fears law; law affects, afflicts, pains our sensuous nature and our natural appetites. The degree and exactitude of the correspondence of the mind with law is not something observed, as from without; it is felt. Felt in a feeling of assent, which is not exultant, not joyous, but is something like inclination--what Kant identifies as purely mental self-satisfaction.

An animate being is one that is activated by itself, that is, by its own representations. Its senses form representations of what happens to affect them, represents them as containing pleasure or pain, which lure or repel the will. The mind obedient to law formulates universal and necessary representations, representations of principles, and these representations function normatively; they order the executive force of life. The mind thinks on command, but it is commanded to be in command. The law is, in Kant's formulation, that one should act in such a way that the maxim represented for your will is universal and necessary.

The mind has to believe then that the representations of principle it presents can activate the will in life's organs and operations. The will energized by sensuous representations is activated from without. For although what lured the will in a sensuous representation is the promise of pleasure it seems to contain, and thus something inward, yet this pleasure is represented as consequent upon contact with something exterior. And the will released by sensuous representations is a will activated by particulars. By the here and the now, the contingent. To such an externally ignited, flickering will the sense of law opposes a will activated by principles its own representational faculty puts to it, and activated by the universal and necessary, a vital will thus activated always and in all circumstances, always in act--an ideal being of the will. Law commands first an inner transformation of the dependent, intermittent, servile human will, that wants, into a self-sustaining, self-maintaining ideal will, that orders. 


\section{The Types of Lawfulness}

But does such an ideal state of the will in fact exist? No one knows. One can give no example. There is no way of determining whether, in any given case, someone who appears to be acting against his own interests and tastes, and in obedience to an inward representation of principle, is not in reality being activated by unperceived external stimuli or unconscious internal drives. In any given case of my own life, there is no way of determining whether, when I represented only the principle to my will, and acted in conformity with what the principle demanded, that was not a mere coincidence, and my psychophysical apparatus was not in reality being activated by imperceptible external processes or unconscious internal impulses. There is, in general, no observation of causality, and, in particular, neither observation of, nor comprehension of, the noumenal causality by which a pure representation of principle could activate the will and the nervous circuitry and musculature of my phenomenal body. Yet I am obligated by the law to imagine myself so constituted that the practical employment of reason would be possible, that I could believe that my psychophysical apparatus could act solely in obedience to law.

Imagination is required--a certain usage of the imagination is required in every case of an action framed in obedience to law. The law is an imperative laid on me; it commands me to frame my psychophysical existence into a succession of positions and actions in the empirical world that would be instances of what is universal and necessary. Syntheses have to be made of the pure idea of the law and the representations of the particularities of the each time contingent situation. For these syntheses, made in advance of the act, one needs what Kant calls "types"--procedures of the imagination to produce a general image. The types are general matrices, like the schemata framed in the theoretical use of reason, but they are practical; they are fabricated to serve as guides in practical judgment. The types have to be constructed by the imagination because, Kant has said, there realiy is no perception of any visible action done by anyone in the world that could reliably be taken to have been framed out of obedience to law, and that could be generalized to serve as a model. In Kant's models the intuitive content is derived not from perceptible human acts, but from the behavior of physical objects, the structure of an instrumental complex, and the operation of the body politic.

A first type derives from the image of the lawregulated clockwork of physical nature. A nature--an object as determined by the natural sciences, or nature as a whole--is a system of elements regulated by universal and necessary laws, the laws of nature. One 
is to imagine oneself making oneself natural--willfully putting an end to the exception, the anomaly, that one's psychophysical apparatus, operating arbitrarily, for its own pleasure, has been. Act in such a way that the maxim put to your will could be represented as a natural law, a universal and necessary law of nature.

The mind is indeed obligated to constitute for itself an objective representation of nature, that is, not a re-presentation of the phenomenal forms that came to birth and die away, but a representation of the external universe as composed of objects which are natures, and which compose nature as a totality determined through universal and necessary laws. This theoretical, or pure, employment of reason is commanded by the moral imperative: the mind finds itself obligated to construct an objective representation of the phenomenal field because it is obligated to represent the world for itself in such a way that it could make sense to be obedient to law in one's operations in that world. What makes the objective representation of nature binding is not its transcendent truth, its conformity with the facts of the things in themselves, but its conformity with the fact of the inner imperative.

In reality to move from the pure sentiment of respect for the imperative to an understanding that the imperative 18 an imperative for law already requires a certain usage of pure reason. The properties of law-the formal properties of universality and necessity-are learned from the formal logic that regulates the theoretical employment of reason in the construction of an objective representation of nature. Logic is used to pass from the primal intellectual feeling of being under an imperative to the understanding that the imperative is an imperative for the universal and the necessary in the practical employment of reason. The imagination commanded by this logic represents the universality and necessity which constitute the form of all nature as a force commanding us to naturalize ourselves.

But is not the agitation produced by sensuous appetites precisely action regulated by universal and necessary laws--those of psychophysiology? To be sure, but there the mind produces representations not of the law in the objects of those appetites, but of the pleasure. The imperative incumbent on the mind requires that one be mobilized exclusively by law. That means that one must no longer take the objects of the external world sensuously represented as termini, as ends in which the will comes to rest, but as means only, an instrumental system that in no way imposes itself or its order on the will. One must not take one's own rational faculty as a means to be put to the service of, and be commanded by, one's own sensuously represented composite nature. The way to not do that is to imagine the whole of external nature, and of one's 
own sensuous nature, to exist as means only and not as ends also, as material, a pure medley of sensuous material, to be ordered by the decrees of the rational agent, and to imagine that rational agency in oneself already existing as a terminus. Kant formulates this type in the words: Act in such a way that you treat humanity, whether in your own person or in the person of another, always at the same time as an end and never simply as a means. The action, he explains, has to be conceived only negatively. It is not: act so as to make your existence the end of all material nature; rather it is: never act against the unconditional worth, or dignity, of your own rational will, never subordinate its existence to any object--or to that sensuous object which is your composite material nature.

The will that commands us to represent objects no longer according to the promise of pleasure with which our sensibility represents them, but only according to the universal and necessary laws with which our pure reason represents them, does not have our own welfare, our survival, in mind by thus excluding from view the seductive conceits of pleasure, the mirage of happiness. But yet we can note that an organism that would naturalize itself 80 as to live in a world of necessity and not in a world of pleasures would no doubt survive, and survive more surely. This would be a sort of anthropological dividend, a species dividend, of individual rationality.

When one acts one is then not to act to appropriate external goods, one is not to act as a predator; one's action is not to be commanded by the particular lacks and contingent wants of one's own nature. One is not to act to make oneself a producer, producing out of the material of nature new substances containing pleasures for one's own sensuous nature. Capitalist action, to produce new needs and new wants in our material and happiness-obsessed given nature, is interdicted by the moral imperative. Action in nature is also not to be conceived as gratuitous--whether as undertaken in order to proliferate dreams and dances in the utilitarian world of things that are means only and not ends also, or to make a dream or a dance out of one's own material nature. Action in nature is not to be conceived as care--as though the ends of nature, of that which grows of itself, could command our will. Rather rational man is obligated to imagine himself as master of nature, sovereign over nature, whose action in nature--and on his own nature--reduces entirely to executive acts, enjoining the layout of external material to everywhere embody the rational decrees formulated within his own subject mind.

But do in fact the real actions one will execute gear into and effect modifications in the layout of things in nature? How could one be assured of any con- 
cordance between the release of the noumenal causality of the rational will with the layout of the things in themselves whose appearances we represent to ourselves as regulated by the universal and necessary laws of objectivity? Could it not remain forever possible that when we believe we have activated our will by a representation of principle contrived by thought alone, and believe that this will has activated the nervous circu1 try and musculature of our bodies, and perceive effects in the external field that seem to be consequent upon that movement and to be in conformity with the principle we had formulated, this is not in fact but a coincidence, and that we are gratuitously believing in causality where there is only the succession of the toady retinue of our own subjective impressions? Yet we have to belleve that it could make sense for us to command our will to realize rationally commanded arrangements in external nature; we find ourselves obligated to believe in a noumenal or ontological destination of the instrumentalities of nature to the decrees of rational volition. We are obligated to postulate the existence of God, creative designer of the kingdom of nature as well as of the ideal realm of the will, in order to be able to believe that such action could be possible, could be real.

The things subject to the noumenal causality of our will have to be imagined as means only--but not means for us to become masters over nature, nor means to satisfy the wants and needs of our nature. They are means for the realization of the ordinances of our rational will. Our sovereignty then consists not in satisfying our nature, but in commanding all nature. It consists in constraining all nature to manifest the laws of our will, but a will upon which the universality and necessity of nature weighs, weighs alone and imperatively.

It will be an analogy with the functioning of civil society that will enable us to imagine this imperative inner ordinance. Rational man must imagine his own inner constitution after the constitution of a political entity that comes to exist and act on its own, not by repudiating the decrees of the mother country or foreign imperial power and disowning all law, but rather by setting up for itself a legislative faculty to dictate 1 ts own laws. Rational man must similarly imagine that the existence of his own will-or its freedom--consists in being bound by laws that are formulated by his own faculty of thought, and not by the laws in effect in external material nature in which his substance is embedded, nor by those that regulate the forces of his psychophysical nature. It is of course not true that one perceives oneself as author of law: law is from the first incumbent on the mind, affects, afflicts the mind, is imposed on the affectivity or the sensibility of the mind, and is not conceived, that is. 
posited in a synthetic a priori judgment. One is not the source of the authority of law in the universe of one's own representation; one rather willfully makes oneself into the locus where cosmic law is articulated and promulgated. But, Kant says, one must, like a citizen in a republic, act as if--one must imagine--one were obeying only laws one had decreed for oneself.

And for others. One is commanded to command oneself, but also to command others and to be commanded by them. The very sense of the other, not only another shape of sensuous material, a physico-chemical apparatus, but a being one can interact with because he is an agent, is the sense of a will in him energized by representations of his own conception. The movements of an organism can also visibly be activated by stimuli affecting it from the outside, or by anonymous impulses arising within. The other exists on his own by act1vating himself with his own representations, representations not only presenting again or in advance external contingencies, but formulating the exigency for law within. To perceive the other is to sense the law that the other imposes on himself. To recognize the other is to respect the other. Respect for others is not respect for their innate composite human nature, but respect for the law that rules in them. Respect is distinguished by Kant from admiration, admiration for the force of perfection of the tangible vital powers in another, which resembles the sentiment of the sublime in physical nature.' The sense of the other as a person is the perception of the action of another as instantiating a law which is valid for me also.

Thus the others concern me, for the principles that govern their actions obligate me too. And, on the other hand, it enters into the very meaning of my own sovereignty that the law that I propose as a maxim for my own practical moves in the phenomenal sphere is a law I legislate for everyone. Acting morally consists in not taking oneself as an exception. ${ }^{2}$ It is to not class oneself among deviants and monsters. It is to make one's moves such that they not only can be understood with the principles common to all reason, but set forth principles binding on all. It is to make every move of one's life exemplary. Concretely this means that action, each gesture, each word, corresponds to a nature represented objectively, in universal and necessary laws, and not to a nature sensuously represented according to the promise of any private pleasure it seems to contain. The existence that the law commands is a commanding existence; it consists in deciding the law with each of one's gestures and moves. Thoughtful existence does not simply obey norms; it acts always to make itself the norm. Each of one's actions becomes juridical; one acts so as to formulate the law for everyone. Sovereign existence is an existence not only 
without particular, private interests, but without privacy, an existence through and through promulgating.

\section{Exemplarity and Veracity}

Moral existence is defined, negatively, as the elimination of the vices of lying, avarice, that is, subjection to material means, and servility.' Positively, it consists first and essentially in honorableness, in veracity, in exemplary publicness." The command of the categorical imperative is to conceive of the maxim of one's own will as a public law; the test of evil maxims is that they have to be kept from public view. Through secrecy one aims at a private life of one's own, which is the direct contrary of autonomous personality. Through dissimulation from others and from oneself one makes oneself "a mere deceptive appearance of a man." Kant cites "even the wish of a lover to find nothing but good qualities in his beloved [which] makes him oblivious to her obvious faults;" such "insincerity in one's declarations, practised against oneself, deserves the strongest censure," as is formulated in scripture, where the original evil and source of all evil is not the fratricide of Cain, but the first lie. Truthfulness devolves not from the material value of truth for theoretical subjectivity. but from the essentially public, exemplary, existence the moral imperative imposes.

It then belongs to the essence of the rational existence that it sovereignly enter into relationship with others. The kingdom--or republic--of ends is formed by internal bonds, it must not be conceived as simple coexistence of free and equal members, where the tangency of their spheres of sovereignty would be "due to the roundness of the earth"'--as though if the surface of the earth were an infinite plane men could be so dispersed that community would not be a necessary consequence of their existence on it."

The society of sovereign legislators must not be imagined as an association through mutual aid, for the reasoned gratification of wants is no longer the motivation of the will among them. Their very rationality is not constituted through mutual aid, as though the consciousness of each could only represent the particular and the contingent, and the representation of the universal and necessary truth could only be constructed by the assemblage of all these particularities and contingencies. Their society is not an association for mutual protection--although, it is true, civil society is first formed in order to guarantee to these lords over nature their sovereign possession of the earth and all its goods, against those who exist in a state of nature; they are indeed obligated to constrain all those in the state of nature to enter civil society. and presumably have at one point formed military asso- 
ciations for this purpose. Yet this motivation does not maintain or define the association of sovereign ones. And their society should not be imagined to exist for production. If these purely rational agents no longer recognize their own happiness as an incentive, they shall also not associate for a productivity that endlessly produces new desires and wants. The kingdom of ends is also not to be imagined after the model of an artist community, whether that which exists for the sake of producing artworks, Balinese, Newari or Nuba societies, or that which makes itself an artwork--the Samurai, the Jesuit order, the Prussian military caste (Nietzsche's examples). In this kingdom the members are existing ends, ends in themselves, and not means, not even for the creation of external splendor or internal sublimity. And their rational sociality does not consist in the ordered circulation of signs--goods, implements, women and messages--in systematically regulated fields. Rational society forms a "nature" through the universal laws that necessitate the movements of each of its members, but the universal laws are decreed by the sovereignly autanomous individuals. Each rational agent is a legislating sovereign, whose word binds all the others. The kingdom of ends is a society whose inner energeia is not the circulation of messages, but the promulgation of decrees.

Positively, action in the republic of ends is imagined as friendship. This friendship is not affection for others, and still less that sensitive enjoyment of their person which is affective love. Moral friendship 18 "the complete confidence of two persons in the mutual openness of their private judgments and sensations as far as such openness can subsist with mutual respect for one another." The kingdom of ends as a friendship of the autonomous sovereigns consists in the reciprocally exposed or manifest life, promulgating each of its deeds in veracity, in confident transparence to others. A friend $I$ am indeed of Plato, but more a friend of the truth. In fact friendship is friendship of truth, friendship in the truth. Eriendship is truthfulness.

The law-promulgating representational mind in me does not only command other minds in the kingdom of ends; it must also command the whole of my material human nature in the kingdom of nature. The imperative for law in me does not only command the pure speculative employment of my reason, that it elaborate an objective representation of nature such that it can be imposed on all minds wherever and whenever they are found; it also commands the practical employment of my reason, it commands me to act in this nature. It commands me to treat all nature practically as in itself a field of means for the rational ordinances of my sovereign will. I am obligated to postulate the existence 
of God, creative designer of the instrumentalities of nature as well as of the kingdom of existent ends, in order to be able to believe that what I represent in my objective representation of nature can undergo the noumenal causality of my will. The kingdom of ends needs this truth. The friendship of the truthful ones, each commanded to formulate always what is binding on all, requires the transcendent validity of their objective representation of the phenomenal order.

4. Nietzsche: The Anthropological Imperative and the Imperative of Nature

Nietzsche has put a question mark on the value of this truth. It is not simply on the worth of the postulate of God that sustains it--for if indeed God himself should prove to be our most enduring lie," his existence is bound up with our grammar." It is the correspondence itself, the truth thus being guaranteed, that Nietzsche questions. Kant, who recognized that not only the secondary properties of the things, but the primary properties also, are phenomenal, exist for us but cannot be said to exist in themselves, continued to suppose that the order upon which the noumenal causality of the will acts consists of things, entities, beings. It is this supposition, for which the creative God is the practical guarantee, that Nietzsche judged to have not truth, but only value--anthropological value. The practical suppositions that there are beings, identities, enduring entities, beings that are the same, Nietzsche recognized to be ontological postulates, transcendental errors, motivated by the logical axioms of identity, non-contradiction, excluded middle, which regulate our objective or intersubjective representation of the phenomena. These fundamental logical axioms and ontological postulates have in fact enabled the species to survive; it can be supposed that countless species with more cautious sensibilities. which did not have the power to judge that any force maintains itself identical from one moment to the next, that what is similar is in fact the same, that a force can be counted on to act as similar ones that seemed to be of the same kind have acted--such more refined, more truthful organisms have perished. The human organism has long since incorporated the fundamental logicoontological errors; its sense organs have become selective, simplifying, falsifying organs. They have come to perceive the phenomenal flux as so many appearances projected from an order of forms of beings, as appearances of beings, self-identical entities, persisting and recurring identities.

This representation is of value, anthropological value, not value to the individual for the constitution of his individuality, but to the species as such, herd value. The speech acts put forth by the individual but 
which function to bind all the others, that action by which the animals endowed with representational thought constitute themselves into an association of ends for which all nature is means only, are made possible by these logicomontological errors.

But Nietzsche goes on to show that the signs of the individual that have the force to bind all the others are from the first the signs of the others, of the species, in the individual. The individual whose moves all lay claims on the others, demand to be recognized by the others, is not the instinctual individual, but the rational individual, and already the conscious individual. Consciousness is the sphere of this imperative of the genius of the species in the individual. Self-consciousness is articulated semiotically. "[T]he subtlety and strength of consciousness [1s] always proportionate to a man's. . . capacity for communication... " 12 Consciousness was developed not under an immanentist, self-appropriative compulsion, but out of a communicative need; what of oneself is mirrored in the sphere of consciousness is that for which one possesses signs. That of ourselves which we have acquired the power to articulate in signs, to verbalize in the inner dialogue of consciousness, is that which we have needed to communicate--our wants, our needs, our impotences. What out of its sovereignty the Kantian autonomous consciousness proclaims to others is not a surplus force produced by its instinctual nature, but the rational force that dominates the cravings of nature, that is, maintains them in their want, reduces them to impotence.

Consciousness was developed not out of a compulsion to discharge the original excess life produces, ife is, but out of the need to communicate wants and requirements; it expresses the shallowest and worst part of ourselves, the surface of vulnerability. The inner dialogue is not conducted in the indicative mode, but in judicatory forms; it formulates the inner processes of life as demands put to another. Consciousness functions not only to position us in the field of gregarity as individual negativity putting demands on the others, universalizing its necessities, but functions as a means to become shallower and weaker. The negativity in terms of which consciousness formulates itself to force the recognition of the other appeals to the will to power in the other, the will to enslave in the other. This is not to be equated with respect for the other; to respect the other is to respect the law that rules in the other: his law, his own destiny. The will to position oneself in the eyes of the others as demand is already a will to be enslaved, the will to make oneself servile.

Consciousness articualtes the imperative laid on oneself into demands put on the other. But the imperative precedes consciousness and does not have as its 
function to make consciousness possible. The imperative is not an imperative of the species, of human nature, but of nature. The imperative force of nature is felt in the measure that the monstrous insipidity of man as the measure of the value of things, as judge of the world, man as a "world-negating" principle is exposed. "We"--Nietzsche says--"laugh as soon as we encounter the juxtaposition of 'man and world', separated by the sublime presumption of the little word 'and'."1" The imperative force of nature on the soul is discovered in the measure that the soul is naturalized, that is, in the measure that it abandons the demand for satisfaction or contentment, "wretched contentment," not its vital compulsions, but its consciousness formulates. "The total character of the world... is in all eternity chaos--in the sense not of a lack of necessity but of a lack of order, arrangement, form, beauty, wisdom, and whatever other names there are for our aesthetic anthropomorphisms... . (H) ow could we reproach or praise the universe? Let us beware of attributing to it heartlessness or unreason or their opposites; it is neither perfect nor beautiful, nor noble, nor does it wish to become any of these things -. "1" To uncover pure nature through a negative labor of de-idealization, de-aestheticization, de-moralization, de-deification Nietzsche fixes as the scientific task of the age.

Positively the essence of all nature is disclosed in the formula of the eternal return of all things, the law which formulates the pure flux of becoming, the irremediable temporality of all things. The law of eternal return diagrams what ontological thought had seen as the infinite distance from nothingness to something that comes to be, the irremissibility of becoming and its irrevocable weight, as a time of the unending recurrence of whatever comes to pass. It formulates the most ancient thought there is, taught already in the most ancient documents of the East and the West, and the most scientific idea, formulating the essence of modern science. The old sciences of the West, formed by the logico-ontological errors, were sciences of forms; modern science is a science of forces; forces explain the forms by their passage and recurrence. Every force in nature, and the total quantum of forces, however immense, is finite; the idea of an infinite force or of an infinite field of forces, force that would bear against nothing, is self-contradictory. But the time in which science situates nature is infinite. If then nature ever had a goal, it would long since have been reached (since nature has already had an infinite time to reach $i t)$; if nature ever aimed at any final state of equilibrium, it would already have been attained, and all movement stopped. The fact that nature is now observably in a state of becoming proves that no such goal is possible. In the infinite exten- 
sion of time all that is possible will be realized, but the tide of becoming cannot be arrested; nature having worked out all its possibilities can only repeat them once again, and innumerable times.

The law is not just a cosmological generalization; it functions imperatively, orders the soul. It is not just a formula, formed by the synthesizing powers of the mind and that can be comprehended by the mind; it is a force, and crushes, or transforms the soul that is forced to contain it. Every 11 fe which is in any way negating with regard to itself, resentful and rancorous, regretful and remorseful, or apprehensive, ansious or hopeful with regard to any of its own states, will feel itself subjected to the irremediableness of all that comes to pass, and sealed in the most desperate kind of despair, that from which the hope for nothingness is taken, that for which suicide is the most lliusory kind of cure. The law is incumbent on me; it is a singular, singularizing law, that makes human existence as such, species existence, impossible. Species existence made possible by the fundamental logico-ontological errors is now seen to have been promulgated in order to give lie to, in order to be the lie that covers over, the truth of the eternal return of all things. The Nietzschean genealogy of morals shows that the aesthetic, religious, theological and scientific representations of the universe in which species existence is installed are contrived by an essentially and increasingly ascetic intellect; the Nietzschean psychology shows that the will's ill will against itself and against time idealized in the aesthetic, philosophic, sacred, sacerdotal and scientific epochs of species history is made imperative in order to give lie to the law of the irremissible becoming, coming from nowhere, going nowhere, of the forces in all forms.

But upon the life that is powerful enough to be able to endure it, the law of eternal return functions to bind imperatively that life to itself, to make it necessary for itself. Every impulse of life turned on the fragments, riddles, dreadful accidents of which its course is composed will become possible only on condition that it is unrestrictedly willed, willed with a will without reservations, without claims, demands or appeals, a will that wills itself without limit. I shall henceforth be able to execute an action only on condition that I can will it without reservation, to the point of willing its infinite reiteration; I shall henceforth be able to feel any feeling only on condition that I can discharge all my forces into it without recompense; I shall henceforth be able to suffer any suffering only on condition that $I$ can die in and of this suffering without regret or pity. The law imperatively makes the soul make itself necessary for itself; it makes it make the singular contingencies--the frag- 
ments, riddles, dreadful accidents--of which it is made imperative for itself.

The soul under the imperative of the law is not motivated by the lure of pleasure, that is, contentment, "wretched contentment," wants nothing and demands nothing of the earth or its gods, is not driven by a will for power. Its will is power, and has the power to will itself unremittingly. It does not will anything other than itself, dces not strive to constitute itself into an exemplar or statute for the genus, does not strive, long for or demand. It sovereignly wills the discontinuous impulses that build and intensify and need only to pass, to discharge themselves, these gratuitious and fortuitous impuses of its existence, as necessary for itself, and makes them necessary by the unrestricted adhesion of will in them.

\section{The Power to be Veridical}

The law functions to make sovereign the soul that has the force, the power to endure it: it also functions to make it truthful. Sovereignty is truthful: the very word noble signifies those who are capable of living by the truth. Their internal constitution is such that they can affirm all that is and becomes-not only the forms formed according to the fundamental logico-ontological axions, our multiplication tables and our grammar read into things, but all that is and becomes and becomes nothing, honey and lees, drunken midnight, tombs and tomb-tears' comfort, gilded evening glow, woe, hell, hatred, disgrace, the cripple, world-"this world, o you know it!"is The soul vast as the world, the soul able to open to the world, would have to be able to affirm itself incessantly, affirm unremittingly its own impulsive passage, all its own impulses which affront, which discharge into, all the fragments, riddles, dreadful accidents of the world. It would have to negate no will that passed in itself nor resist any will to come. Such a soul is no longer a portentous power of negativity, but wholly self-affirmation.

This soul has to learn the new Zarathustran way to "carry together into One what is fragment and riddle and dreadful accident." 16 The way of metaphysics, the way of comprehension, is to make the elements, unknowns, contingencies of the universe into one by composing into a totality, a system, their meanings. The way to affirm what is is to affirm its meaning. Metaphysical comprehension is the enterprise of exhibiting the universal meaning of the particulars, the system composed by all the fragments, the finality and necessity of all the happenings, the affirmation composed by all the negations, rendings and death. "Death - . is of all things the most dreadful, and to hold fast to what is dead requires the greatest strength," 
Hegel wrote. "But the life of spirit is not the life that shrinks from death, and keeps it untouched by devastation, but rather the life that endures it and maintains itself in it... ISJpirit is this power only by looking the negative in the face, and tarrying with it. This tarrying with the negative is the magical power that converts it into being." for his part does not believe in this magical power of the dialectical mind, to convert the pain, transience and death of all things into the ideal subsistence of meaning. His genealogy shows this magical conversion into meaning and ideality, the dialectical cleverness which could, like divine reason, abominable spider. weave all things together with rational connections, reckoning a goal and purpose for each thing within the whole, to have been in truth the systematic devaluation of transience and of all transitory things. This reckoned relating is a relativizing, an affirming of each thing as means only and not as end also. Nietzsche does not come to teach a more clever way still to contrive meaning for all things, and thus affirm them. His affirmation will consist not in subordinating them, through meaning, through significance, to one another and to the whole, but in affirming the worth of what has no significance, in affirming as an end unto itself what does not serve another. What Nietzsche has found is an affirmation of all things through affirming their value." Value and meaning are no longer identical. To apprehend the value of something is not to grasp its referentiality. Value is no longer instrumental or teleological; to affirm value absolutely is not to affirm that something is an end relatively, in view of something, or in view of the rational designs of sovereign man; it is to affirm that it is an end in itself and not for us.

The law functions imperatively to bind the soul to itself unreservedly, to make it unremittingly affirmative in its own inner constitution, and thus able to affirm the value of, to love all the impulses upon which the fragments, riddles and dreadful accidents of the world press; it gives the soul the power to be truthful. But is the law itself truthful?

\section{The Truth of the Law that Imposes Veracity}

Eternal recurrence is, Nietzsche says, the most scientific idea, the final idea produced by the structure of all modern science, the idea that formulates the ontological diagram of ali that science knows. But Georg Simmel already in 1907 produced a model for the universe composed of a finite number of entities but destined to endure an infinity of time, which would be in continual motion and yet never return to any given position; it would be enough to set in motion on an axle three wheels turning at speeds of $n, 2 n$ and $\frac{n}{\pi}$. is 
To this one could object that such a universe would be constructed out of entities, whereas the Nietzschean-the modern scientific--universe is rather constructed out of processes. Arthur Danto has then argued that every process which proceeds continually from state 0 to state $n$ passes through a flux of transition infinitely divisible; a universe made of two such processes could proceed through an infinity of time without ever reproducing any given configuration they form. 20

To this one might first try to object, with Heidegger, that the Nietzschean law of eternal return is an ontological and not empirical law, and can be neither confirmed or invalidated by the empirically observable. The law of the eternal return of all things concerns the way of being of all that is, not only the objects of nature, but also the essence of the subject himself, the inner diagram of the most truthful soul. But as a law formulating what it means for the objects of cognition--of scientific congnition--to be, to be in becoming, it is a cosmological law, or what Husserl characterizes as a law belonging to the formal and a priori ontology of nature. Its formulation as a cosmological law is the means of access to an ontological thesis; that is why Nietzsche could determine to go to Paris to study physics for ten years in order to make himself the teacher of the law of the eternal return of all things. The simmel and Danto arguments are not empirical determinations; they are epistemological considerations whose effect is to show that the law of eternal return is not a cosmological law built into the structure of our science. This law does not belong to the totality of all that which we know, which we determine to be true.

Nietzsche did not publish any reference to the law of eternal return which tried to argue it as a cosmological law; only in notes which he chose not to publish did he discuss the possibility of establishing it scientifically. What he published were texts that consider the force, the effect of this thought upon the soul that thinks it. "What if some day or night a demon were to steal after you into your loneliest loneliness and say to you .... If this thought gained possession of you, it would change you as you are or perhaps crush you..." But what if the law of eternal return were false? Were to not belong to the system of all that which we know, our science? What if the law of eternal return were the lie that makes the soul trutheul?

The law of the eternal return of all things is not a metaphysical law; it does not formulate the essence of the things in themselves beneath their phenomenal surfaces; it rather is an ontological law, law formulating the essence of being-way of becoming--of the appearances themselves. It is the internal law of pure nature--as opposed to the human-all-too-human represen- 
tation of nature which the Nietzschean genealogy has shown to have been elaborated pragmatically. for its utility and not for its truth. It is the law of the pure surface, the phenomenal mantle that phosphoresces about the most comprehensive soul, the truthful soul, as opposed to the representation of nature constructed according to the fundamental logico-ontological errors by the esentially mendacious intersubjectivity, the genius of the species. Nietzsche certainly took it to be the law that rules in the modern scientific representation of the universe as an electromagnetic field of forces divested of all teleology. The simmel and Danto arguments have not established that it cannot be, only that it need not be.

Yet science is not the only access to pure nature, true nature: there is enlightenment in religion. Not in the modern religion, to be sure, the moral religion, Platonism for the usage of the people, with its imprecatory perception which perceives the world as accursed, its penal interpretation of the construction of the universe, its juridic and executive God who is dead, who is death, formula for immateriality, immobility, intemporality, formula for the pure contradiction of 1 ife and sentence formulated on all that lives. This religion is not enlightenment, but cult of conscience, guilt culture. Nietzsche's first work is devoted to the psychoanalysis. of the enlightenment found in the old religions, in particular the tragic culture which theoretical, dialectical, Socratic, optimist culture supplanted, which it was contrived in order to destroy. Nietzsche concentrated the powers of his analytic tools on the actor of the tragic age, not the actor of laborious, progressive, technological culture, who transforms the forms of the world, but the non-serious agent, actor who only transforms his own forms. The analysis is not concerned with the cognitive content of the subjectivity of the actor, the question of the truth-value of his representations; in fact the whole of the phenomenal universe this consciousness objectifies and regulates about itself is only phenomenal, phantasm, false. What is taken seriously is not the ideas and forms that occur to the actor's consciousness, but his feeling, his pleasure. What is the specific pleasure of the actor, pleasure of this most superficial man, who is anybody or nobody, who represents everybody, who uses all his forces only to transform his own form, or, more exactly, to give form to his life, to contract the figure and the coherence and the necessity of an identity, a perfection, a destiny, making every intonation of his voice, every position of his glance, his fingers, his torso, every contingency of his complexion, his profile, his size and shape and color significant, telling, essential? His pleasure is creator's pleasure, pleasure of creating a form of life, but it is a pleasure that is not 
diminished when that form of life has been brought to its completion, its perfection, its end, for the actor feels in himself the force to reproduce that form, or another, the following night. This pleasure functions as metaphysical consolation--consolation for our grief, for the mortality of every form of life, and of our own form. It is the ecstatic pleasure known by the Dionysian initiate who comes in the night not to renounce his civic identity in the indeterminism of nocturnal dissolution, but rather to exchange robes and roles and destiny in a promiscuity of generalized transvestitism, subject into king and king into subject, man into woman and woman into man, human into satyr and satyr into human, slave into god and god into slave. And this pleasure, this expulsion from every stasis, is deep. In communicates with, indeed issues out of, the joy of nature--and nature is powerful and joyous, and all joy is natural, and the upsurge of the natural in us. The natural joy consists not in the maintenance of certain forms, but in the continual creation and destruction of forms of life--I believe the old Teutonic saying, Nietzsche wrote in his youth, all the gods must die.

Thus, in the midst of a mind being employed to produce a representation of nature which is phenomenal, phantasmal, false, without transcendent truth and even without anthropological, species, value, there is produced a pleasure which is deep, which is ontological, an illumination which has ontological veracity.

The progressive, optimist, theoretical culture that was contrived to supplant and to repress the tragic, prehistorical ritual culture abolished this enlightenment. But we live in a time of reminiscence; Nietzsche himself is a reminiscence of rituals long discredited and of an enlightenment long forgotten. The historical sense is the distinctive virtue and disease of our age. To many the historicism, the relativism, engendered by the historical sense is the instrument of a great impoverishment and coldness, the extinction of the old fires that illuminated the dawns of the great visionaries; to others it is the sign of stealthily approaching invalidism and the senility of a philistine theoretical civilization. But to Nietzsche the will to assemble all the history of humanity to make it our own history is the distinctive means produced by our culture for the production of power, for the passage to absolute spirit. But for that the historical sense must not be formed dialectically, retaining of the past and the bygone its meaning, depending on the dialectical fecundity of meaning to engender a future for itself, and on the dialectical assemblage of all meanings to put us in possession of all that can be. Nietzsche does not believe in memory and in the dialectical fecundity of meaning; he believes rather in the fecundity of forces, instinctual and unconscious forces, 
compulsion to dream and compulsion to dance, forces that regain their strength once precisely they have been forgotton, liberated from their meaning, from the chains of meaning.

We of the present day are only just beginning to form the chain of a very powerful future feeling, link for link--we hardly know what we are doing . . . Anyone who manages to experience the history of humanity as a whole as his own history will feel in an enormously generalized way all the grief of an invalid who thinks of health, of an old man who thinks of the dreams of his youth, of a lover deprived of his beloved, of the martyr whose ideal is perishing, of the hero on the evening after a battle that has decided nothing but brought him wounds and the loss of his friend. But if one endured, if one could endure this immense sum of grief of all kinds while yet being the hero who, as the second day of battle breaks, welcomes the dawn and his fortune, being a person whose horizon encompasses thousands of years past and future, being the heir of all the nobility of all past spirit--an heir with a sense of obligation, the most aristocratic of old nobles and at the same time the first of a new nobility--the like of which no age has yet seen or dreamed of; if one could burden one's soul with all of this--the oldest, the newest, losses, hopes, conquests, and the victories of humanity; if one could finally contain all this in one soul and crowd it into a single feeling--this would surely have to result in a happiness that humanity has not known so far; the happiness of a god full of power and love, full of tears and laughter, a happiness that, like the sun in the evening, continually bestows its inexhaustible riches, pouring them into the sea, feeling richest, as the sun does, only when the poorest fisherman rows with golden oars! This godlike feeling would then be called--humanity.21

The historical sense is not a consciousness constituted by the dialectical assemblage of all the meanings of all the past deeds of mind; it is rather the feeling produced by the accumulation, the compression into one soul, of all the griefs, melancholies, despairs, boldnesses, welcomes, exultations, inebriations of all past spirit; not the synthetic integration of all these forces-their compression, their juxtaposition, the maintenance of them in the cauldron of one' $s$ own soul. Nietzsche does not envisage a progressive constitution of a historical consciousness through active recall and memory: what is at stake is rather the return of feelings, the return of the savage and nomadic compulsions 
that have long been extinct and the instincts of the blond beasts that dreamt the old dreams that have long been forgotten. The most comprehensive soul Nietzsche envisages is the place of this return.

The historical sense is our participationist ritual, our transvestitism and our form of orgy. It is now not called metaphysical consolation, but beatitude. the highest form of spirit, divine subjectivity, the happiness of a god full of power and love, full of tears and laughter, not the happiness of fulfillment, contentment, wretched contentment, and not that of tranquililty, equilibrium, quiescence and bliss, but ecstatic exultation, ecstatic squandering. It would be at the same time natural, like the sun, hub of nature, subject to an imperative of expenditure without recompense. The identity of spirit and nature would then be called humanity; it is total humanity in the individual, which knows the world, has been broken on all its fragments, understood all its figures as riddles, needed all its contingencies. This most comprehensive soul is truthful, not because it fabricates for itself a representation of original nature and then observes the correspondence of its representation with that original; rather it itself corresponds with the forces of nature, it is constituted as the space of a return of all the visionary and intoxicated intensities of history which responded and corresponded to the sweep and countersweep and ebb and flood of nature. There is correspondence, concordance between the divine happiness of that soul and the joyous force of all nature. Which correspondence is fixed in the emblem of eternal return, both the most ancient and the most modern form of philosophical doctrine, both the most universal cosmological law and the most singular, singularizing, law.

One will demand now to know: How is this correspondence produced? Whether this correspondence is an exact one? How is the exactitude of the correspondence known?

The correspondence is produced by nature in our nature. The soul does not make itself truthful through an asceticism and a discipline performed on itself, through an active synthesis of all the possible affirmative forces which bear the faces and figures of every noble, that is, truthful, life of history. The soul does not make itself truthful through a productive imagination which positions it in an ideal kingdom of ends, commanding all, commanded by each. The most comprehensive soul is rather the locus of a return of atavist compulsions and long forgotten instincts. As in the tragic rituals of enlightenment, it is when the ego, sovereign legislator, or representative of the republic, is steeped in unconsciousness, drugged or intoxicated, that there is a resuryence of forces of nature in his nature. It is to his withdrawal outside 
of all culture, to the loneliest heights of nature, his long proximity with the sun hub of nature, that zarathustra owes all his wisdom.

That which proves the correspondence is an exact one is the indefatigably powerful, unreservedly affirmative state of the soul in which it is produced. It is not the inner labor of negativity which determines, which terminates, which makes into terms, entities, identities, beings, that is capable of knowing the world, but the soul become capable of affirming all its own impulses that arise fortuitously and discharge and demand nothing from the fragments, riddles and dreadful accidents that press upon them, from hell, hatred, disgrace, the cripple, world--this world, oh, you know it! The radical absence of every negativity, every reactivity, resentment, regret from the soul ensures the exactitude of 1 ts correspondence with the world.

The exact degree of truthfulness of the soul is not known out of a comparative estimation of that which would be formulated in an image of its inner constitution and of that formulated in the formula in which the essence of the world is conceived--representations which would themselves be produced by that soul. Where the will to truth is founded on the compulsion to decree the meaning of each of one's acts as a law binding everyone, the one who appraises the aptness of any maxim of his own will to be a universal law for every rational nature can only be one decreeing what his appraisal formulates. The veracity of the soul corresponding with its law can be known to itgelf only through an inner adhesion of that soul to itself as its law opens it upon the world. This adhesion can have negative or positive quality--can be resentment, negativity, pain inflicted on itself, or assent to itself. "This ultimate, most joyous, most wantonly extravagant Yes to life represents not only the highest insight but also the deepest. "22

\section{NOTES}

IImmanuel Kant, Critique of Practical Reason, trans. Lewis White Beck (Indianapolis: Bobbs-Merril1, 1956), p. 79 .

${ }^{2}$ Imuanuel Kant, Groundwork of the Metaphysic of Morals, trans. H. J. Paton (New York and Evanston: Harper and Row, 1964), pp. 91-92. 
'Immanuel Kant, The Metaphysical Principles of Virtue, trans. James Ellington (Indianapolis: BobbsMerrili, 1964), pp. 90-98.

"Ibid., pp. 90-92.

'Ibid., p. 91.

'Ibid., p. 92.

'Immanuel Kant, Metaphysik der sitten (Berlin: Koniglich Preussischen Akadamie der Wissenschaften, 1916), p. 457.

\section{Ibid.}

'Immanuel Kant, The Metaphysical Principles of Virtue, op. cit., p. $13 \overline{38}$.

"Friedrich Nietzsche, The Gay Science, trans. Walter Kaufmann (New York: Vintage, 1974), par. 344.

"Friedrich Nietzsche, Twilight of the Idols, trans. Walter Kaufmann in The Portable Nietzsche (New York: Penguin, 1954), p. $\overline{483}$.

${ }^{2 F r i e d r i c h ~ N i e t z s c h e, ~ T h e ~ G a y ~ S c i e n c e, ~ o p . ~ c i t . . ~}$ par. 354 .

"Ibid.. par. 346.

"Ibid.. par. 109.

"Friedrich Nietzsche, Thus Spoke Zarathustra, trans. Walter Kaufmann (New York: Penguin, 1978), IV, par. 19, 11.

"Ibid, II, par. 20.

"G.W.F. Hegel, Phenomenology of Spirit, trans. A. v. Miller (Oxford: Oxford University Press, 1977), p. 19.

"Eriedrich Nietzsche, The Gay Science, op. cit., par. 301.

"Georg Simmel, Schopenhauer und Nietzsche: Ein Vortragzyklus (Leipzig: Dunckler and Humblot, 1907), pp. $250-51$.

20 Arthur Danto, Nietzsche as Philosopher (New York: Macmillan, 1965), pp. 203-209.

par. 341.

"Eriedrich Nietzsche, The Gay Science, op. cit.. 
${ }^{22}$ Eriedrich Nletzsche, Ecce Homo, trans. Walter Kaufmann (New York: Vintage, 1967), p. 272. 